\title{
Rhythm in Ethiopian English: Implications for the Teaching of English Prosody
}

\author{
Anegagregn Gashaw \\ Department of English Language and Literature, Wollo University, Dessie, Ethiopia \\ E-mail: ganegagregn@gmail.com
}

Received: $15-12-2016$

Accepted: 28-01-2017

Published: 31-01-2017

doi:10.7575/aiac.ijels.v.5n.1p.13

URL: http://dx.doi.org/10.7575/aiac.ijels.v.5n.1p.13

\begin{abstract}
In order to verify that English speeches produced by Ethiopian speakers fall under syllable-timed or stress-timed rhythm, the study tried to examine the nature of stress and rhythm in the pronunciation of Ethiopian speakers of English by focusing on one language group speaking Amharic as a native language. Using acoustic analysis of the speeches recorded from four Amharic speaking learners and two Canadian native speakers of English, comparison was made between pitch contours and length of speeches between speech samples of Amharic speakers with native speakers who are used in this study as a point of reference. The result of acoustic analysis showed that Amharic native samples displayed actual peaks on almost all words, taking longer time of articulation. It can be said that acoustic measures the study used for prosodic assessment of Ethiopian English exemplified the most occurring production tendencies of pronunciation that learners should give attention to. English pronunciation teaching to Ethiopians should involve the practice of stressing, un-stressing and rhythm to help learners improve their pronunciation from the influence of the syllable-timed rhythm of their mother tongue.
\end{abstract}

Keywords: Ethiopian learners, rhythm, pronunciation teaching, pronunciation learning, Amharic learners, English as a foreign/second language

\section{Introduction}

Rhythm is often associated with a kind of periodicity, or a recurrence of certain patterns of color, design, or sound at regular (equal) intervals of space or time. For example, in music, rhythm is usually produced by making a certain kind of beat in a sequence standing out from others by being louder, longer, or higher at equal intervals of time (Roach, 2001). As Roach (Roach, 2002: 67; Roach, 2001: 36) puts it, rhythm in language, likewise, refers to the periodic recurrence of certain patterns of sound in utterances, “...syllables take the place of musical notes or beats, and in many languages the stressed syllables determine the rhythm".

It has been claimed that in some languages of the world, syllables constituting utterances, whether accented or unaccented, tend to occur at equal time intervals (Batibo, 2000; Dalton and Seidlhofer, 1994; Jenkins, 2000; Roach, 2001). The time taken from one accented or stressed syllable to the next will be in proportion to the number of unaccented syllables between them. Such languages are said to have syllable-timed rhythm. Some other languages of the world, on the other hand, have stress-timed rhythm. In these languages, accented syllables have a tendency to occur at approximately equal intervals of time, irrespective of the number of unaccented syllables intervening between one accented syllable and the next.

According to this theory, English, for example, belongs to the second category of languages and has stress-timed rhythm (Roach, 2002: 36). This would mean that, in English utterances, accented syllables tend to occur at approximately equal intervals of time. On the other hand, "unstressed syllables between the stressed syllables are squeezed into the time available, with the result that they may become very short" (Roach, 2001: 36).

To see the performance of rhythm more closely and its relationship with accent as well, it is important to examine 'rhythm units' (O'Conner, 1980: 90-100). It is noted that when groups of words are spoken continuously, a sort of break or pause occurs after a group, but not during it (O'Connor, 1980). Similarly, Roach (2002: 52), explains it as tone units that "... continuous speech can be broken up into units called tone units [emphasis original], and that each of these will have one syllable that can be identified as the most prominent". Within each word group or tone units, there is at least one stressed syllable. These stressed syllables in a group may have one or more unstressed syllables before them, and these unstressed syllables are said very quickly to make them short. Meanwhile, the stressed syllable in a group may be followed by one or more unstressed syllable. However, these unstressed syllables 'are not said specially quickly, rather share the amount of time which a single stressed syllable would have' (O'Connor, 1980: 96). For example, English words "nine", "ninety", "ninetieth" all take about the same time to say "nine"; so do these sentences such as "I am here", "I was here", and "I was in here" in such a way that "the unstressed syllables are all very short, as short as you can make them.' (O'Connor, 1980: 96). 
In his explanation of the fundamental rule of stress-timedness, O'Conner (1980: 98) says, 'each stress group within a word group is given the same amount of time' (i.e. stressed syllables together with any unstressed syllables which may follow it form a stress group). For example, in a sentence "both of them left early", 'both of them' is one stress group, 'left' is another and 'early' is another; all taking the same amount of time.

On the other hand, in cases of unstressed syllables before the stressed ones as in "I am going home", for example, it is noted that there are two stress groups 'going' and 'home'. The first syllable 'I am' does not belong to any stress group since it comes before the stress, and it is said very quickly, quicker than the unstressed syllable in the stress groups (O'Connor, 1980). This pattern contributes to the stress-timedness of English as described by O'Conner (1980:99) as follows: "In this sort of arrangement, any unstressed syllable before the stressed syllable is said very quickly and doesn't affect the length of syllables before it".

It is the unit of this kind, with a stressed syllable as its center followed or preceded by any unstressed syllable is called rhythm unit (ibid). For example, according to O'Connor (1980), in "I am going home for Christmas", there are three rhythm units: 'I am going', 'home', and 'for Christmas', each having stressed syllables on 'going', 'home', and 'Christmas' respectively (O'Connor, 1980: 90).

Not all languages have similar rhythmic pattern because some of the world languages have syllable-timed rhythm (Roach, 2002: 67; Roach, 2001:37). Phoneticians have already claimed that English is of stress-timed and therefore learners of English as a second or foreign language who belong to syllable-timed rhythm should learn those patterns of English pronunciation, which are foreign to their native language rhythm. In Ethiopia, for example, there are more than 80 local languages and Ethiopian learners of English may speak any of these languages as a mother tongue. However, there seems to be no much work done available that provides the rhythmic patterns of these languages particularly with regard to the world's two broad dichotomy: stress-timedness and syllable-timedness. For instance, the pioneer works on Amharic grammar by Baye (2000) and Getahun (1990) addressed the phonology of Amharic with predominant focus on its segmental aspects while no considerable mention was made on the intonation and rhythm aspects.

If we should help learners in Ethiopia to improve their pronunciation in English, one thing we should do with respect to rhythm is to identify whether or not the learners' mother tongue has the same rhythmic pattern or different with English. Because Ethiopia is a multilingual country, we cannot deal with all of them in one study like the present one. Therefore, this study only addresses the issue in terms of one language group named 'Amharic'. The selection of Amharic in this study is purposive as the present researcher speaks Amharic as a first language.

The question of whether Amharic is syllable-timed or stress-timed came to the researcher's mind when conducting his $\mathrm{PhD}$ dissertation 4 years ago while investigating Amharic Speakers' intelligibility of spoken English to native English speakers (Anegagregn, 2012). The study was concerned with unintelligibility estimates and recommended future researches closely investigate what it is that may facilitate or debilitate intelligibility in spoken English between Ethiopians and other groups of speakers (i.e. both native and non-native English speakers).

Previous studies on English as a foreign/second language pronunciation have often taken into account learners' mother tongue phonological differences with target language phonology in their quest towards exploring difficulty areas in English pronunciation. In order to identify problem areas of English pronunciation for foreign/second language learners and help learners pay attention to these problems in their learning and become familiar, contrastive analysis between the phonology of English and that of the learners' mother tongue has been one research area for both practitioner teachers and theoreticians. In this regard, a couple of studies in Ethiopia contrasted the phonology of Oromipha and Amharic with that of English (Anegagregn, 2014; Italo, 1988). Anegagregn (2014) for example contrasted both segmental and suprasegmental aspects of English and Amharic and identified possible difficulty areas of English pronunciation for Amharic learners. Among other factors, stress is found to be one of the typical aspects of English pronunciation that Anegagregn predicted as potentially the most important problematic area of English pronunciation for Amharic speaking learners.

Whether Amharic is syllable-timed or stress-timed in its rhythm is not, however, verified by previous studies. Anegagregn (2014) for instance left the issue of the Amharic rhythm unanswered with mere speculation that Amharic is syllable-timed if it is not stress-timed. Such definition of the rhythm of the world's language is common in the literature as depicted by O'Connor (1980) as well that 'everything non-stress-timed is syllable-timed'. However, these claims should also be verified through actual production data taken from speakers. Accordingly, this study explores the nature of stress and rhythm in the speeches produced by Ethiopian learners speaking Amharic as first language, and verifies whether Amharic is stress-timed or syllable-timed.

\section{Method}

Using speech analyzer software, called PRAAT (6.0.20), the study employed acoustic analysis of the speeches recorded from four Amharic speaking learners and two native speakers (two females and two males) and two native speakers (one female and one male) of English. All participants took part in this study voluntarily. A read aloud technique was used for recording what the participants were asked to read aloud, which was the sentence, 'You have to be so early if you want to find a parking place'. Native speakers were used in this study not as a parameter and a goal to aim at but only as a model to compare with the rhythmic patterns of English. 
Utterances by females were digitally filtered of $300 \mathrm{~Hz}$ pitch ceiling and $100 \mathrm{~Hz}$ pitch roof while those by males at 250 $\mathrm{Hz}$ and $70 \mathrm{~Hz}$ pitch ceiling and roof respectively. Gender specific range settings prior to analyzing the voice samples are mostly used in previous studies for the efficiency and speed of acoustic measure (Abebayehu, 2007; Nagamine, 2002). Such pitch floor settings dictate that sounds in a speech sample below or above this frequency will be ignored. Research involving prosodic assessments mostly used gender specific low-pass filtering technique $(70 / 100 \mathrm{~Hz}$ roof $-250 / 300 \mathrm{~Hz}$ ceiling) that removed most of the segmental information from the signal, while leaving rhythmic and intonational features largely intact (Nagamine, 2002).

Acoustically, stress or accent features are detected by the change of pitch level or pitch prominence while intonation consists of the occurrence of recurring pitch patterns (Gimson, 1980; Roach, 2001). The acoustic correlate of pitch is fundamental frequency Fo measured in cycles per second and represented in $\mathrm{Hz}$ (Hertz). Hence, Fo measures of the pitch of each syllable and Fo shapes displayed in the PRAAT picture window were utilized to investigate the sample speeches stress and rhythm tendencies. Besides, visible pitch contour displayed in PRAAT were also employed for the analysis.

\section{Results and Discussion}

Pitch prominence of the sample speeches was detected in 'draw visible pitch contour' window where the point of time, syllable and word which received the highest peak or pitch prominence is shown. By pointing the syllable of each word where the highest peak or shape is shown, each utterance was therefore analyzed as to the respective words where change of pitch level or prominence occurred. In other words, the highest peaks across the contour showed those words where syllables were accented (Gimson, 1980).

Both native speakers tended to segment their speech into five syntactic groups as 'you have to be/so early/ if you want /to find/ a parking place'. As can be seen in the natives' visible pitch contour below, both native speakers showed a falling pitch shape at the end of each unit or segment; the direction of their pitch changed downwards somewhere at the words of 'be', 'early', 'want', 'find', and 'place' which received stresses. This pattern of segmenting or dividing an utterance or longer string of speech is common in natives' speech and is known to facilitate listeners' ease of processing and interpreting information (O'Connor, 1980). Those words under the same group or segment are called tone groups or information units.

As displayed in the following figures, both native English speakers showed gradual fall to the lowest point at the last tone group on the last word 'place' probably to mark the end of their speech. Meanwhile, both native speakers tended to show pauses of approximately equal intervals between the tone groups $(0.35 \mathrm{sec}$.), and even between stressed syllables in each tone group $(1.5 \mathrm{sec}$.). Such approximately equal interval of time across stressed syllables and between tone groups gave a regular and consistent rhythm to the native speakers. This specific rhythm, which is generally described as stress-timed rhythm, is often described as a backbone for English intonation (O'Connor, 1980). Thus, English is generally described as an intonation or stress-timed language.

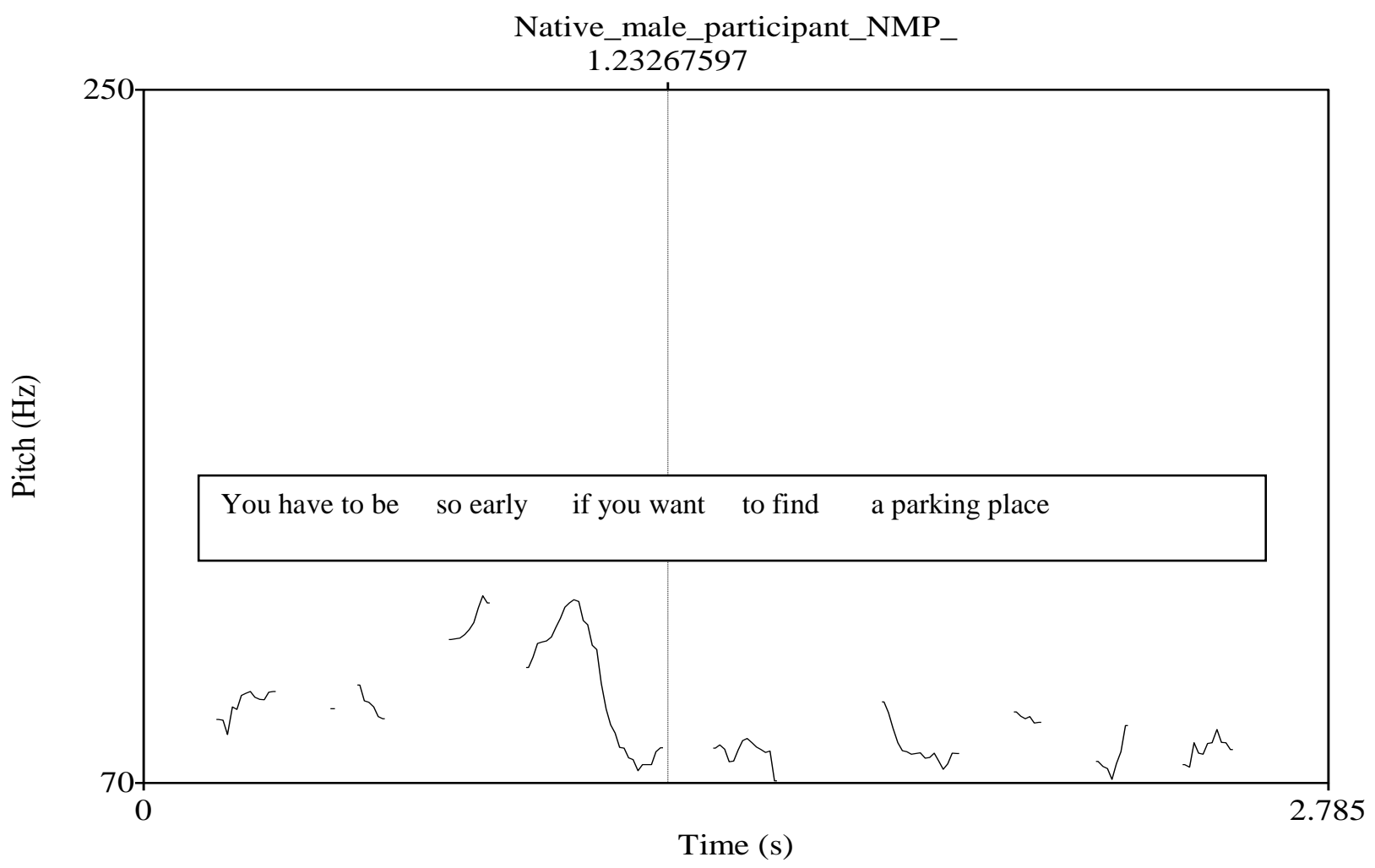

Figure 1. Pitch contour of native participant 1 (NP1) 


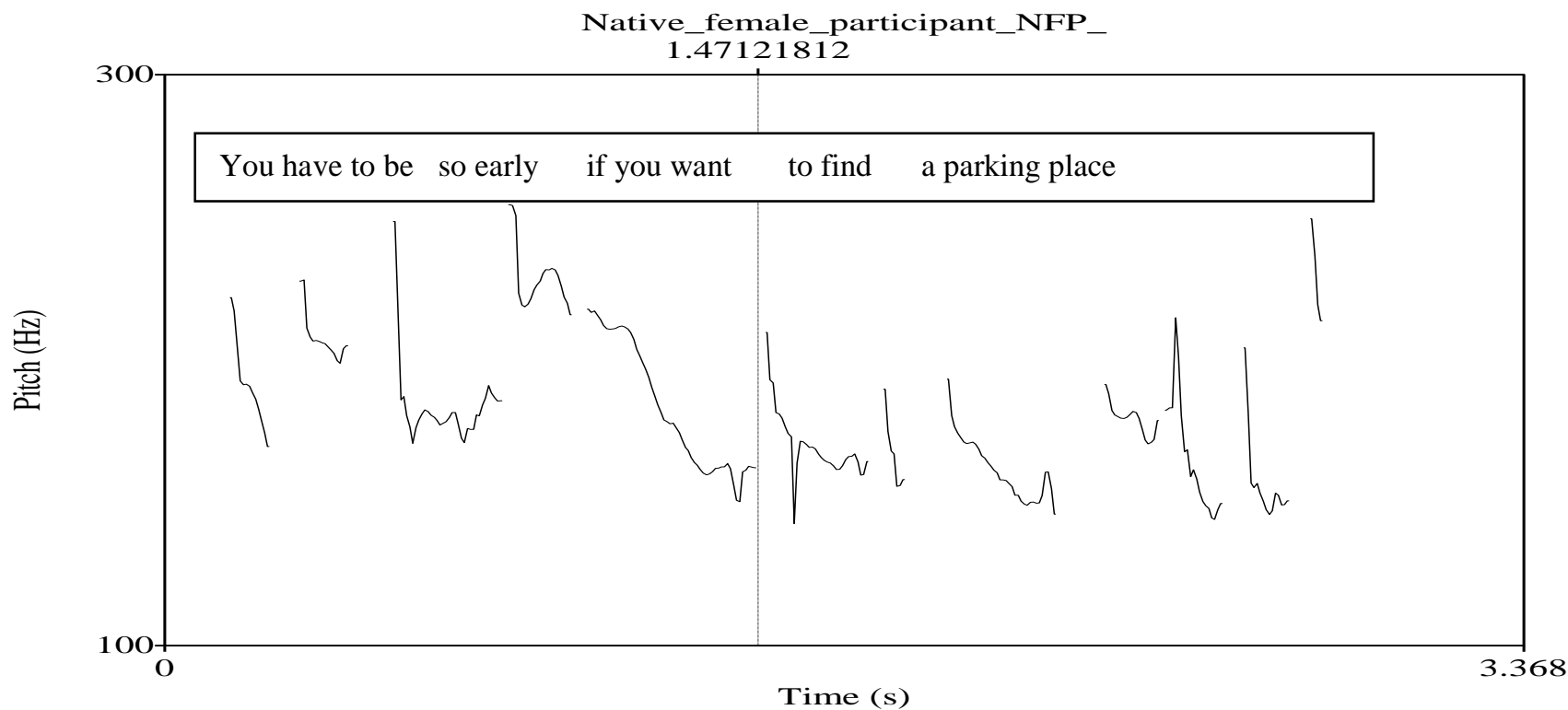

Figure 2. Pitch contour of native participant 2 (NP2)

On the other hand, unlike the native English speakers, Amharic native samples displayed actual peaks on almost all words in the sentence. Each of the syllables in the words was clearly or loudly audible taking adequate and approximately equal time in their articulation. As a result, actual peak was shown at almost all syllables throughout the utterance. In other words, all words in the sentence seemed to receive stress. Such a pattern of putting stress at all syllables is not common in English speech as demonstrated by the native speaker participants.

As compared to the native speakers who uttered the unstressed syllables very fast, the Amharic native samples took longer period of time (on average, 4.5 seconds for their utterance) than that of natives who took an average of 2.5 seconds. One possible reason for this may be that the native samples uttered the unstressed syllables very fast while the Amharic native speakers took equal length of time on all syllables.

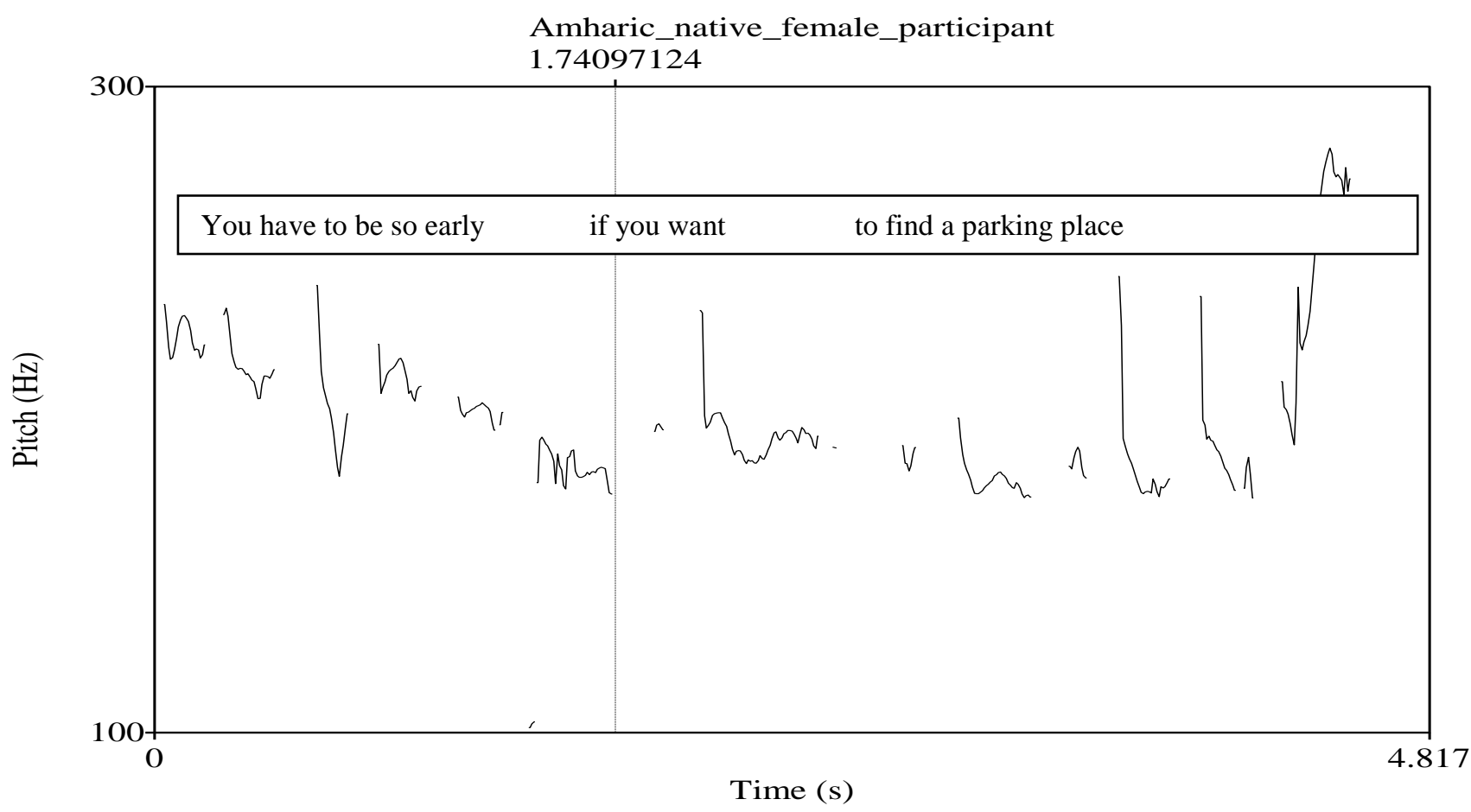

Figure 3. Pitch contour of Amharic native participant 1 (ANP1)

Some variations were also observed in the tendency of segmenting the speech into tone or information units. For example, the Amharic speaker presented above divided her speech into three segments as 'you have to be so early/ if 
you want/ to find a parking place', giving her utterance a bit of inconsistency with the number of words, the length of time, and the syntactic structure of the units as well.

Similarly, more inconsistent patterns of segmentation and contour shapes were observed in the other three Amharic speakers. One of the male speaker (ANP3), as the figures below presents, for example, spoke 'you have to be so early if you want' as one tone group with a falling pitch while 'to find' and 'a parking place' used as different tone groups.

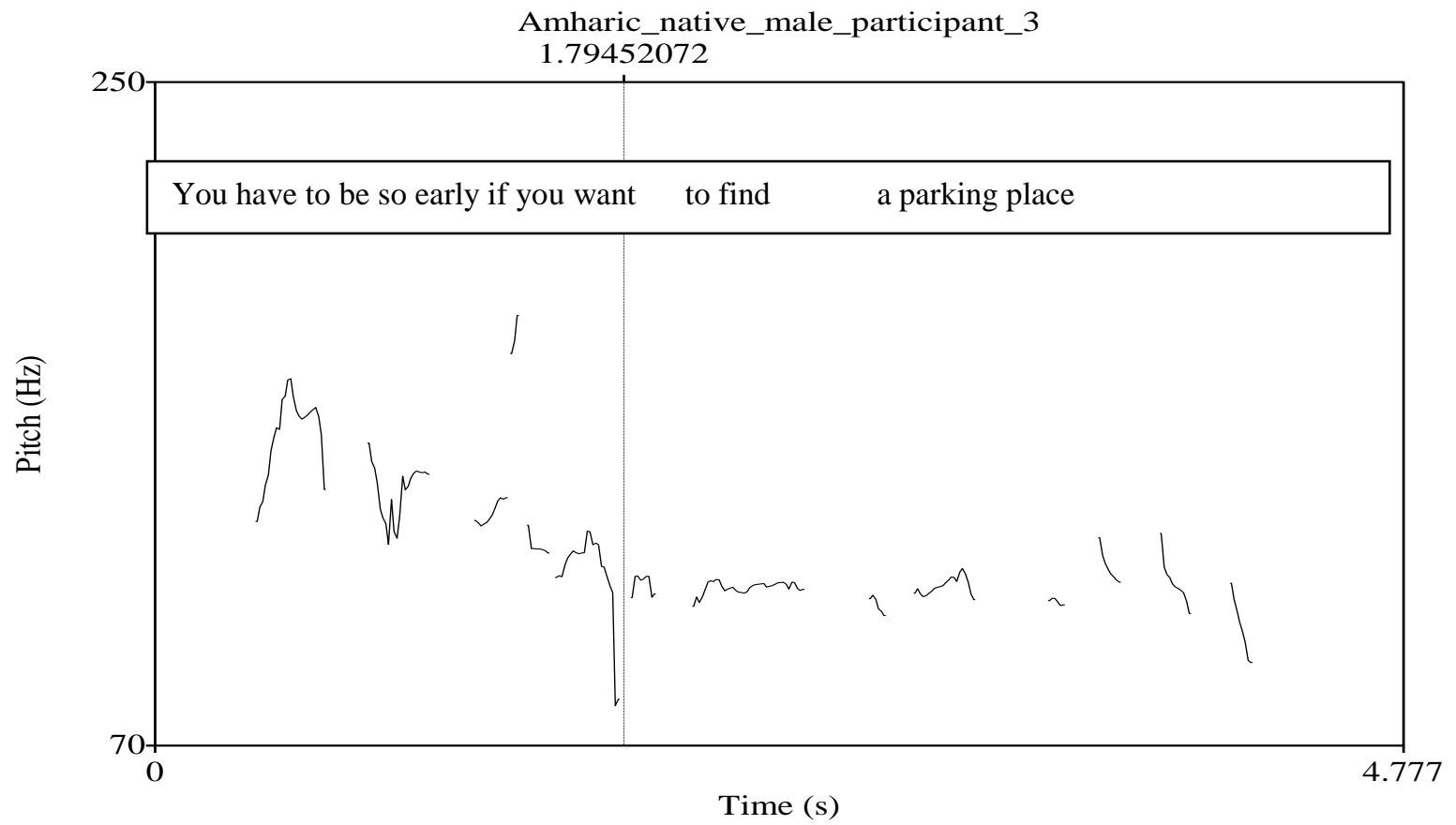

Figure 4. Pitch contour of Amharic native participant 3 (ANP3)

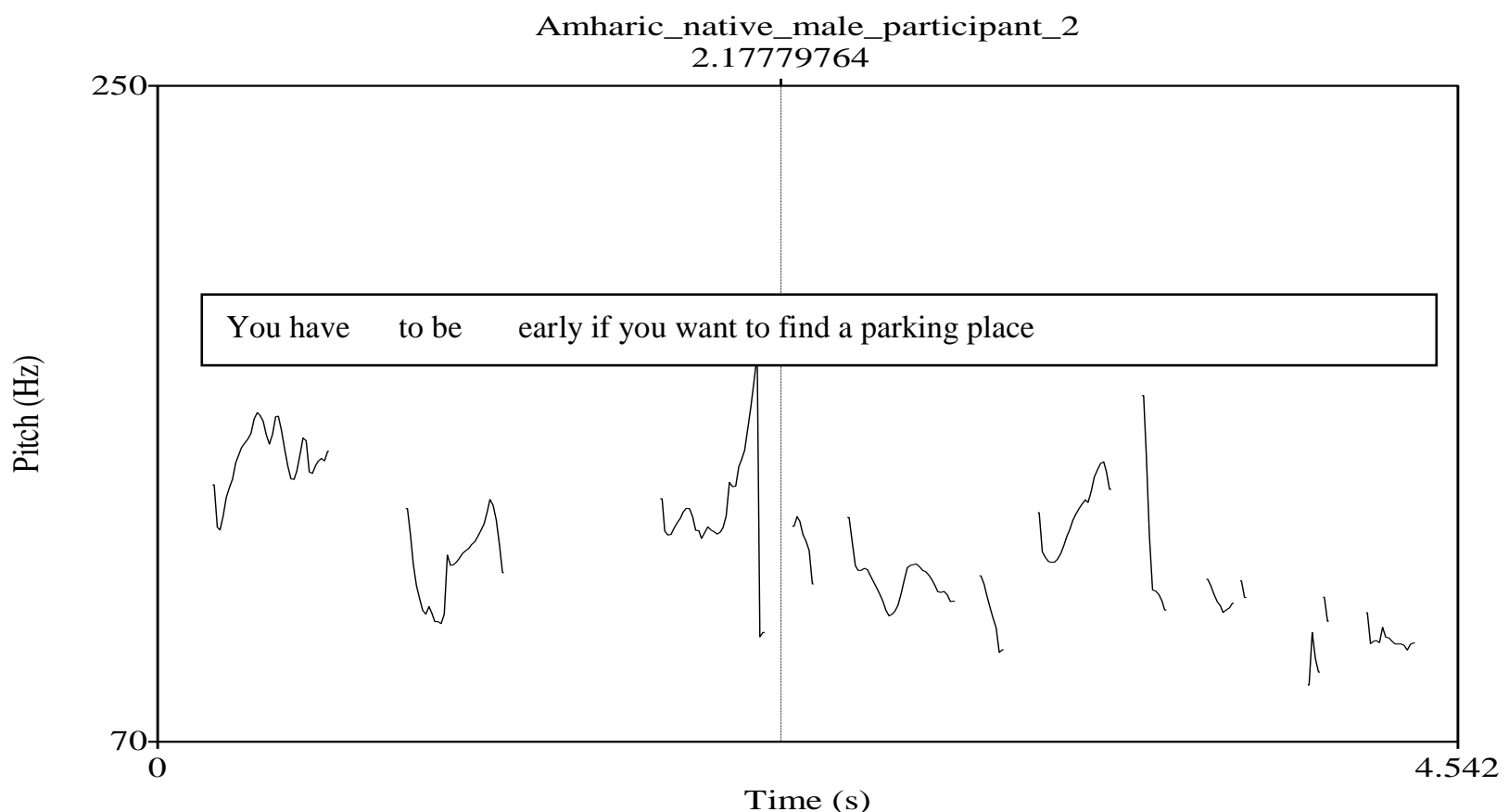

Figure 5. Pitch contour of Amharic native participant 2 (ANP2)

\section{Conclusion}

The study tried to see the nature of stress and rhythm in the speeches produced by Amharic speaking learners of English and compared it to the speeches produced by native English speakers. Speech samples were taken from speech productions of the Amharic speakers and native English speakers collected through read aloud speech elicitation techniques. Speech samples derived in this way were analyzed for prosodic accounts as measured objectively as acoustically analyzed using PRAAT (Boersma, 2001). 
The prosodic measures and pitch contours resulted from computer assisted acoustic analysis reveal that sample speeches taken from Ethiopians disclose differences in many ways when compared with the native speakers.

One is syllables in the sample speeches produced by the Amharic speakers are assigned approximately equal amount of weight, regardless of whether the syllables are stressed or unstressed. As a result, Amharic speakers' pronunciation of English may sound as what Gimson (1980: 40) describes, "staccato-like to the native speakers ears". According to Gimson, this particular type of rhythm can adversely affect the comprehensibility of their English to the native speakers. On the other hand, in the speech samples representing native English speakers, no $F_{O}$ measure was observed on those syllables such as 'to', 'if', and ' $a$ '. The repeated play on the position of the sentence at these words revealed very fast articulation following or preceding the stressed words that receive actual peaks. The syllables receiving no pitch measure and said very fast are called unaccented syllables (Roach, 2001).

The other important characteristic of Amharic speaker' pronunciation that was found to be different from that of Native speakers of English was segmentation of utterances into units/groups. Not only did variation occur between Amharic speakers on the segmentation of the entire speech into information units but also the direction of the pitch displayed at the end of each group varied between units and speakers as well. The data shows that the Amharic speech is also segmented but lacks rhythm at equal interval/timing because of inconsistencies on the number of words, the length of time, and the syntactic structure of the units as well. Variation among Amharic speakers can be demonstrated from the sample speeches depicted in the data by one speaker (ANP3) as 'you have to be so early if you want' as one tone group with a falling pitch while 'to find' and 'a parking place' used as different tone groups; while another participant (ANP2) began his speech with short tone groups as 'you have' with a rising pitch and the next 'to be' with 'fall-risefall' pitch contour followed by a long last one of 'early if you want to find a parking place'. Both of these speakers (ANP2 and ANP3), however, showed a falling contour at the end of their utterances.

On the contrary, segmenting their speech consistently into syntactic groups, i.e. as 'you have to be/so early/ if you want /to find/ a parking place', was commonly displayed in both samples of the native speakers. Meanwhile, both native speakers tend to show pauses of approximately equal intervals between the tone groups $(0.35 \mathrm{sec}$.), and even between stressed syllables in each tone group $(1.5 \mathrm{sec}$.). Such approximately equal interval of time across stressed syllables and between tone groups gave a regular and consistent rhythm to the native speakers.

To sum up, speech samples collected through read aloud speech elicitation techniques were acoustically analyzed using PRAAT for prosodic assessment. It can be generally said that, unlike that of the native speakers, the Amharic native speakers did not display consistent pitch contour and information unit segmentation, which probably tended to show a different intonation and rhythmic pattern across each utterance. Besides, each showed pitch contours different from the native ones who showed approximately similar and consistent pattern. In addition, the time interval between pauses were so irregular and longer which sometimes make the utterance, as for example shown in two of the Amharic native speakers (ANP1 and ANP2), full of interruption or hesitation.

On the whole, then, the acoustic analysis of $F_{O}$ measures, actual peaks and pitch contours between native English and native Amharic speakers provided basic prosodic features of each utterance. Particularly, those patterns of stress, rhythm, and intonation of the samples were objectively measured showing the speakers' characteristic tendencies of their prosody. The result generally revealed that the Amharic native samples showed no similarity with stress, intonation, and rhythmic patterns as shown in the native speakers. It must be noted here however that the acoustic differences on the part of the Amharic natives' speech samples from that of native English speakers were only used as indices of stress and rhythm in Ethiopian speeches but not as goals to be aimed at.

The findings have important implications for teaching and learning of languages. One point to note here is that learners of English as a second or foreign language, particularly those from languages of syllable-timed background, are expected to face some difficulty in English rhythm. Phoneticians, therefore, suggest that adequate practice in this area is very important to the learner, and to ignore it would be to neglect a vital aspect of English pronunciation (Dalton and Seidlhofer, 1994; Jenkins, 2000; Kenworthy, 1987; O'Conner, 1980). Almost all writers put forward that not following the rhythmic pattern of English would make one's speech difficult to follow and to understand as well, which may lead to loss of intelligibility.

It is true that same first language speakers have developed a shared background be it cultural or linguistic, and therefore, the rules regarding their pronunciation in general and rhythm in particular is common. So understanding between interlocutors may not be difficult. However, in an international context, speakers do not share the same knowledge and thus communication become complex. In situations like in Ethiopia where Ethiopians are likely to communicate with native English speakers (or proficient non-native speakers), not only does their speeches sound 'staccato' but also they will not comprehend what is actually conveyed to them. Therefore, to communicate effectively at international contexts, Ethiopians as speakers and listeners are expected to work up on some flexibility and awareness on the stress-timed nature of English pronunciation.

The importance of rhythm and stress in Ethiopian Teaching English as a Foreign Language (TEFL) program should not be ignored. Students should be able to develop sensitivity to English stress and rhythm while teachers should be prepared to help their students to accomplish better performance in an international environment. Meanwhile, some feasible ways of training on stress and rhythm should be in place. 


\section{References}

Abebayehu, M. (2000). An Acoustic Analysis of a Pathological Speech: The Case of an Amharic Speaking Person with Flaccid Dysarthria. (Unpublished M.A. Thesis). Addis Ababa University, Addis Ababa.

Anegagregn, G. (2014). Potential Problematic Areas of English Pronunciation for Amharic Native Learners Based on Phonological Contrast between the Two. Ethiopian Journal of Education, 34 (1).

Anegagregn, G. (2012). Ethiopian Learners' Pronunciation Difficulties and Intelligibility of their Spoken English: Speakers of Amharic in Focus. (Doctoral Dissertation). Addis Ababa University, Addis Ababa. Accessible at etd.aau.edu.et/bit stream/123456789/2126/3/.

Batibo, H. (2000). The sounds of Africa: Their phonetic characteristics. In V. Webb, \& Kembo-Sure (Eds.), African Voices: An Introduction to the Languages and Linguistics of Africa (pp. 133-159). Oxford: OUP.

Baye, Y. (2000). Amharic Grammar. Addis Ababa: Eleni Publishing Ltd.

Boersma, P. (2001). Praat, A system for doing phonetics by computer. Glot International, 5, 341-345.

Boersma, P., \& Weenink, D. (2010). Praat: Doing phonetics by computer [Version 5.1. 35, Computer program]. Retrieved June 10, 2010.

Dalton, C., \& Seidlhofer, B. (1994). Pronunciation. Oxford: OUP.

Getahun, A. (1990). Modern Amharic Grammar. AA: Nigd Publishing.

Gimson, A. C. (1980). An Introduction to the Pronunciation of English. Edward Arnold Publishers LTD.

Jenkins, J. (2000). The Phonology of English as an International Language. Oxford: OUP.

Kenworthy, J. (1987). Teaching English Pronunciation. London: Longman.

Nagamine, T. (2002). An Experimental Study on the Teachability and Learnability of English Intonation Aspect: Acoustic Analysis on FO and Native Speakers Judgment Task. Journal of Language and Linguistics, 1(4), $362-399$. O'Connor, J. D. (1980). Better English Pronunciation. Cambridge: UP.

Roach, P. (2002). A Little Encyclopedia of Phonetics. http://www.personal.reading.ac.uk/ llsroach/peter/

Roach, P. (2001). Phonetics. Oxford: OUP.

Roach, P. (1991). English Phonetics and Phonology: A Practical Course. Cambridge: CUP 